\title{
Personal Accounts of Mothers' Use of Social Media to Support Abstinence from Alcohol
}

\author{
Suzanne McGarva, Tony Machin \\ Northumbria University, Newcastle, UK \\ Email: suzannemcgarva@icloud.com, tony.machin@northumbria.ac.uk
}

How to cite this paper: McGarva, S. and Machin, T. (2017) Personal Accounts of Mothers' Use of Social Media to Support Abstinence from Alcohol. Journal of Biosciences and Medicines, 5, 67-80. https://doi.org/10.4236/jbm.2017.512008

Received: July 24, 2017

Accepted: December 8, 2017

Published: December 11, 2017

Copyright @ 2017 by authors and Scientific Research Publishing Inc. This work is licensed under the Creative Commons Attribution International License (CC BY 4.0).

http://creativecommons.org/licenses/by/4.0/

(c) (i) Open Access

\begin{abstract}
Alcohol consumption by professional educated women and mothers is rising. Drinking alcohol in the home is, for many, becoming a normalised and daily ritual. Previous research focuses on causality, risk factors and health related damage. Few studies focus on mothers of school age children specifically or why some mothers pursue and sustain alcohol free lives. The role of social media in enacting and sustaining abstinence is under researched, as are other factors important for this group in remaining abstinent. Aims: This qualitative study explored the reasons why mothers drank alcohol, and factors contributing to their decision to become alcohol free. It also explored the value and utility of social media in the form of a specific web-site aimed at providing support in abstinence. Methods: Six UK mothers with school age children who had become abstinent after previously drinking over official limits were recruited via a social network website and interviewed. Transcripts were analysed thematically and inductive themes emerged. Results: Participants used alcohol to self-medicate, as a reward/relaxation strategy and because it was a normal part of their professional and daily lives. Reported reasons for abstinence included the negative effects alcohol had upon lives, inability to moderate/drink within guidelines and "trigger" events. Participants reported that their use of social media was inspirational, giving them a platform to share stories and help others and was preferred to traditional support. The use of social media in this way represented a supportive community and assisted vigilance toward the danger of relapse. Positive parenting identity, alternatives to alcohol, abstinence rewards and support from abstinent others were all factors in sustaining abstinence. Conclusions: Health professionals should recognise this hidden and hard to reach group and the potential efficacy of social media in assisting recovery from alcohol related issues.
\end{abstract}

\section{Keywords}

Alcohol, Drinking, Professional Women/Mothers, Support, Social Media, 
Abstinence

\section{Introduction}

Alcohol consumption among women in the UK presents an ongoing concern [1], with women in professional roles drinking more heavily/frequently than comparators [2]. Alcohol is promoted and normalised by the media, with $40 \%$ of UK Television broadcasts involving images of alcohol [3]. Women's magazines market alcohol alongside positive images and messages. There has been a cultural shift in the UK whereby higher levels of alcohol consumption in the home are normalised [4].

For professional women, alcohol can be integral to friendships and workplace networking, within which context women may not identify as having problems.

"Coping" models suggest alcohol assists with stress, enhancing positive mood and/or decreasing negative mood. Other factors contributing to women's motivation to drink include previous trauma such as physical/sexual abuse and/or domestic abuse [5], stressful life events [6], and comorbidity with affective disorders as "self-medication" [7].

As adult social roles become prominent, it is often assumed that people "mature" out of heavy alcohol use. However, evidence suggests that for many, alcohol use is part of everyday life and acceptability is based around ability to function rather than quantity consumed. Home drinking is also considered socially acceptable, convenient and a marker of transition from work or parental responsibilities to "me time", with alcohol being a standard part of the food shop [8].

"Self-changers" have been found to be aware drinking was an issue prior to initiating change [9]. Research has commonly found negative experiences such as shame, health, financial consequences and crisis precipitate positive change behaviour [10]. Women cite guilt attached to the effect their drinking has on their children as a motivator [11]. Not all motivating factors are negative, positive associations have been found between beliefs regarding benefits of stopping/reducing alcohol intake and likelihood of making a change attempt [12]. Factors predicting sustained abstinence centre on improved quality of life, including dimensions of employment and personal relationships [9]. Factors sustaining positive behaviour change are thus different to the factors which act as triggers addressing original issues, with recovery seen as more than simply abstaining.

Many people with problem alcohol use never seek professional help [13]. Traditional approaches such as Alcoholics Anonymous can be seen negatively by women, with "drinking as disease" stances undermining self-efficacy [14]. Women can constitute a hard to reach and hidden group with mothers' drinking in particular seen as blameworthy, shaming women when they drink as much as men [15]. These factors, together with fear of losing children can also prevent 
mothers from seeking help [16].

\section{Social Networking as a Potential Support Factor}

The influence of social support in recovery is well known [17]. It has been argued that positive role models can enact change behaviours in others [10]. When drinking is addressed without professional help the term "natural recovery" is used, and it has been suggested [18] that this is more common than treatment assisted recovery. Online social media support forums have become increasingly popular for support with addictions, particularly for those reluctant to seek traditional help [19]. For women, the internet is rapidly becoming a major source of health information [20]. Social media/networking is increasingly part of everyday lives, rising from $45 \%$ in 2011 to $61 \%$ in 2015 [21].

Online forums offer supportive environments in an immediate, convenient, safe and anonymous way [22]. The web site which was the focus of this research, called here "support site X", is one such social network website, a non-religious, peer support online resource for women with alcohol issues.

\section{Methods}

\section{Research Aim}

An exploratory, qualitative/narrative approach was adopted with mothers who had used a social media support network in sustaining abstinence from alcohol for a period of at least one year. This allowed exploration of their alcohol free journey with the complex and iterative process of change emerging directly from personal narratives [23]. Research aims were as follows:

- To explore the reasons why mothers drank alcohol;

- To explore why mothers became abstinent;

- To explore the value and utility of social media (specifically "Support site X");

- To explore factors important in sustaining abstinence.

\section{Methodology}

\subsection{Participants}

Participants were recruited via a "gatekeeper". Launched in 2012, "support site $\mathrm{X}$ " is a social media vehicle promoting alcohol free living, offering support for women wishing to address drinking behaviours and remain abstinent. By 2013 the site had more than 20,000 members worldwide, many of them professional middle class women and mothers. Information indicating the focus of the research and inclusion criteria was posted within the bi weekly email that "support site X" circulates. Prospective participants were self-selecting, and provided with an information sheet including ethical considerations and issues of informed consent. On acceptance an agreeable time for telephone interview was arranged. A final sample of six mothers was recruited. Interviews took place between March and April 2015. Five UK based mothers identifying as White British and one as Irish were recruited. All were cohabiting, aged between 33 and 49 years 
old with between one and three children under age 16. All but one were educated to at least graduate level, all were in professional positions, previously drinking six or more drinks on one occasion at least weekly but were abstinent for the past year or more. Previous reported drinking levels ranged from regular daily drinking to bingeing, with some consuming in excess of 100 units per week. All reported that they were unable to moderate consumption within guidelines prior to abstinence. Three described unhappy and abusive childhoods that included parents with alcohol issues and/or mental health issues, the remaining three described happy childhoods and no exposure to parental alcohol issues.

\subsection{Data Collection Methods}

Pseudonyms ensured anonymity, with demographics collected at the beginning of the interview. Semi structured telephone interviews were employed, questions designed to encourage participants to tell their story and guide their narratives relating to the research aims. Follow-up questions encouraged elaboration. Telephone interviews were chosen as they avoid geographical/transport constraints, they may also facilitate honest and open responses with less prospect of embarrassment or fear of judgement. Interviews lasted between 50 and 90 minutes and were digitally recorded and transcribed with potentially identifiable information omitted.

\subsection{Data Analysis}

Narrative enquiry is powerful in understanding the "why" behind human action [24]. Thematic Analysis was chosen to identify central themes for each participant and the data as a whole. Braun and Clarke's [25] guide to thematic analysis was followed, encompassing familiarisation with the data and transcription, generation of initial codes, searching for themes, reviewing themes and finally defining and naming themes.

In judging qualitative approaches, Pistrang and Barker (2012) outline criteria of trustworthiness, credibility and transferability of findings [26]. These criteria were held in mind, together with Elliot et al.'s [27] seven guiding principles addressed to encourage focus upon systematic process. The underpinning philosophy and research approach frees the sample from the constraints of fixed response questioning inherent in quantitative studies, allowing the influences of relevant environmental, personal and social factors to emerge. It is acknowledged, however, that this sample was self-selecting and may differ from any notion of "target population" in terms of insight, motivation and views.

\subsection{Researcher Background}

At the time of research, the first author was a psychology graduate educated to Master's level working within an NHS Public Health Directorate in Scotland. The research forms part of the requirement for a Master's in Public Health. The 
second author was supervisor of the research.

\section{Results}

\subsection{Why Mothers Drank Alcohol}

Normalised: Drinking was described as a normal part of working life, encouraged and viewed as coming with the job. So long as it did not interfere with work commitments, you could drink as much as you liked:

“... sales meetings were very much geared around drinking ... free bars, lots of people getting very messy ... general rule of thumb that you could get as messy as you wanted as long as you rocked up to the meeting the next day." (Lucy)

Drinking was a normal part of everyday home life:

"... me and (partner) always drunk a lot together as a couple so it was sort of the thing we did." (Edna)

"... no one felt we had a problem cos we all drank the same." (Lucy)

Self-medicating. Drinking could be a form of self-medicating for stress:

"... have it in a tea mug ... if it was too early to have it in a glass ... the stress of trying to make everything perfect and worry for everybody and organise everything." (Abigail)

Or to manage grief, anxiety or depression:

“... because my life had changed so much ... I got quite depressed and I started drinking really heavily..." (Jenny)

"To relieve anxiety when I was alone." (Anna)

Those who had experienced unhappy and abusive childhoods believe this contributed:

"I drank cos I had a really shitty childhood ... my birth father exited the stage when I was very small ... (my) stepdad was an alcoholic ... my mum ... has mental health issues ... my real father ... is also an alcoholic..." (Lucy)

Reward and relax. Drinking could be a reward or entitlement after a busy day:

"I deserved it, I work hard ... those first few glasses ... do taste great, relaxed, get all mellow and yummy and gorgeous and relaxed and chatty." (Abigail)

\subsection{Why Mothers Became Abstinent}

A range of reasons were described which contributed to becoming abstinent:

Negative effects of drinking. This theme led to four sub themes:

1) Physical health:

"I thought I was turning menopausal ... I was having night sweats and hadn't realised that it was the very early start of physical addiction..." (Lucy)

2) Shame and guilt:

“... horrendously guilt ridden wondering who I needed to apologise to, had we had to leave early, had I let myself down, what did people think ... horrible flashbacks." (Abigail)

3) Parenting:

“... I would wake up feeling like absolute death ... and think P ve got 12 hours 
of this, they ${ }^{2} d$ (children) be making a noise ... and $1 d$ just sit there thinking can you stop making a noise..." (Edna)

This was echoed by another mother talking about her daughter:

“... racing through stories cos I was just thinking about wine ... I couldn't be bothered doing stuff with her ... I was teaching her your only happy when you' re having a drink." (Charlotte)

4) Mental health effects: Negative mental health effects were experienced whilst drinking, particularly anxiety and panic attacks:

"I was a very anxious person ... if I was going for a big session the anxiety, the fear, that you get after that ... anxiety is one of those things that's really bad when you drink." (Jenny)

Moderating was not possible: Previous unsuccessful attempts to moderate drinking were a factor:

"... started playing the moderation game ... became a real cycle of stop, do ok and then fall off and binge ... (it) taught me ... moderation just doesn't work." (Lucy)

Failure to moderate or drink within guidelines could lead "light bulb" moments that abstinence was the way forward:

“... I couldn't moderate ... what's so bad about being teetotal anyway so why was I so afraid of it ... maybe I do, just do need to stop drinking completely and (I) was becoming open to that idea..." (Anna)

Triggers. Specific events could trigger a decision to abstain:

“... drove home drunk ... I was clearly over the limit and ... shouldn't have driven... that really frightened me..." (Abigail)

"... woke up (in hospital) ... it was right, that's me and booze done ... no deliberating, I was terrified I knew I could have died." (Charlotte)

\subsection{Value and Utility of Social Media (Specifically "Support Site X")}

\section{Looking for inspiration:}

"I was trying to look (online) for role models ... other mums who had stopped drinking ... like if they can do it, I can do it." (Anna)

After finding the website "support site X", mothers described how they could relate and identify with others on the site:

"(The) typical person ... on [support site X'] is 'well I ve got a good job, got couple of kids, got a loving husband, $P \mathrm{~m}$ drinking almost every night and it's really worrying me now that kind of model was me." (Edna)

A variant of the term "sober" is used in the title of "support site X", and was perceived to be more positive and empowering than typical words attached to alcohol problems:

“... I remember thinking ... I d hate to be an 'alcoholic' ... I don't like negative labels; I prefer to call myself a [term for membership of the site].... works better for me to look at it in a positive light." (Charlotte)

Helping others: "Support site X" provided an avenue to share stories and ex- 
periences to help other people in the same position:

“... write about my experience (on 'support site $X$ ) as a kind of positive thing for other people." (Jenny)

Preferred to traditional support. "Support site X" was preferred over traditional support. Four sub themes emerged:

1) Easy to access: The site is easily accessible:

"I can sit on the sofa and do it so $1 \mathrm{~m}$ not having to go to a meeting; I can just sit there and link in when I want." (Edna)

2) Better suited to individual needs: "Support site X" provides a more encouraging service than traditional services:

"It's not the stick, it's the carrot, nothing about the liver, weight, me getting strokes if I drink two glasses of red wine ... it's about more education about the fact you could actually exist without alcohol." (Abigail)

“... generally what's out there is pretty homogenous ... for me ['support site X'] was specifically aimed at women like me." (Charlotte)

3) General Practitioners (GPs) Unhelpful: GPs were not always seen as helpful:

"... they were prescribing anti-depressants ... he (GP) said 'you know try and cut your drinking down or just half fill the glass ... and say that's all you' re going to have' ... you ... stand back and think that's not the way that it works with somebody like me." (Jenny)

Consulting the GP in relation to drinking worried some:

“... women go online much more cos of the implications going to a GP ... child protection boards ... what happened in $80 \mathrm{~s}$ when they went in and took children and its scares everyone to death." (Lucy)

4) Alcoholics Anonymous (AA) Unhelpful: Those with experience of being to AA found it depressing and unhelpful:

"I had been to AA and thought to myself oh god this is not me ... I don't want to be surrounded by these people every day or twice a week ... you need to look at it in a more positive way." (Jenny)

Others found it inconvenient and overtly religious:

"... that puts a lot of people off ... cos it's more secular attitude to religion." (Lucy)

"Support site $X$ " as a Supportive Community: The site provided a support network:

“... there was no one else I could talk to really ... I often talked to them it is like being part of a community..." (Abigail)

The site also provided immediate and personal support:

"... I put on (the site) that I was struggling and could anyone help, someone personal messaged me who was 10 years sober ... and we' ve kept in touch." (Anna)

"Support site X" Keeps me Vigilant. The site promotes vigilance against relapse:

"Somebody came on and said 1 ve just relapsed after ... 10 years and I remem- 
ber feeling quite shocked ... so it made me feel this is a lifelong thing really." (Edna)

\subsection{Factors Important in Sustaining Abstinence}

Positive parenting identity: Being a good parent and role model to children can help sustain abstinence:

"Now they have a very positive role model in me ... my children, they are so thrilled that I don't drink ... now they have great consistency." (Abigail)

Finding alternatives. Since becoming alcohol free the need to find alternatives to alcohol is important:

"I went to ... yoga ... it really did make a big difference ... and it still does now." (Edna)

"I go for a run ... go to the sauna and I always come back more relaxed so it does work." (Abigail)

Abstinence rewards. A sense of gratitude and freedom can be evident:

"I constantly think' thank you for my alcohol free life' ... am grateful ... it's just such a gift ... freedom..." (Abigail)

For others the rewards were better mental health;

“... I can start the day feeling positive and happy ... alcohol (was) damaging my self-esteem, giving me anxiety..." (Anna)

Other reinforcing rewards are more physical including sleep, physical appearance, motivation and weight

"sleep it just transformed even now waking up without a hangover it's just a gift everyday ... I lost $10 \mathrm{lbs"}$ (Lucy)

Support from abstinent others. Support from people who have been in the same position and are now abstinent was particularly important;

"... for me one of the most powerful things in helping me stay stopped was just reading others peoples experiences that mirrored my own ... peer support from other people" (Charlotte)

This includes the importance of distancing from drinking environments;

"a lot of my friends still are quite heavy drinkers ... if they are arranging a night out Pll just say ... don't put me on the list..." (Jenny)

\section{Discussion}

\subsection{Why Mothers Drank Alcohol}

In exploring motivations for drinking, three main themes emerged indicating alcohol use is normalised, self-medicating and rewarding/relaxing. Drinking during or after work was quite normal, in engrained drinking cultures with opportunity and acceptability. For some, alcohol was important in work contexts for networking, reflecting findings elsewhere [28]. Drinking was also normalised out with employment.

Drinking was reported as self-medication to cope with stress, depression or anxiety, lending support for "coping" models. Within this sample, though by no 
means representative statistically, half indicated abusive/traumatic backgrounds, and the other half indicated happy "normal" childhoods. Affective problems were described by all, with alcohol used to cope, supporting previous evidence that affective disorders commonly co-occur with alcohol dependence in women [29].

Mothers talked about a sense of reward/relaxation after a busy day as employee and parent, again reflecting other research findings [30], and supporting a "multiple burden" hypothesis whereby complex multiple social roles lead to higher stress levels and increased alcohol use [31].

\subsection{Why Mothers Became Abstinent}

These mothers were aware their drinking was an issue prior to initiating change, and cited negative effects of mental and physical ill health, shame and guilt as influences in their decision to abstain. In accordance with findings elsewhere [11], the negative effects drinking had on parenting and the associated guilt were both motivational factors. Mothers who had witnessed and experienced their own parent's alcohol misuse did not want that for their own children, resonating with other research [9]. Ineffective attempts to moderate alcohol intake also constituted a factor in the decision to abstain.

There were also very specific triggers, most of which were negative such as drink driving or hospitalisation. This reflects two of Klingemann's [32] categories within a typology model of motivation to stop drinking; "hitting bottom" and "cross road" types. It should also be emphasised that, as found in previous research [10], this research also found positive triggers, such as taking inspiration from others recovering from alcohol dependence.

\subsection{Value and Utility of Social Media}

These women actively searched online for support, reinforcing the idea that relatively few problem drinkers seek professional help. Some had sought professional support, albeit briefly, before finding "support site X". Despite alcohol problems, these women were maintaining skilled employment, meeting their commitments but had recognised they were drinking to hazardous or harmful levels. This contradicts some previous findings [8], whereby the ability to meet ongoing commitments reinforced the tendency to dismiss issues with alcohol despite drinking above guidelines. It has been argued [33] that shame and embarrassment may make women with alcohol problems a hard to reach, hidden group. This could account for why the women in this sample cite "support site X" as somewhere to look for inspiration and others who were or had been in the same position. This supports other findings [10], whereby positive role models can enact change behaviours in others. Women talked of relating/identifying with others using "support site X", and preferring the terms relating to sobriety rather than "alcoholic". This reframes negative, potential esteem eroding aspects of drinking to positive, more inspiring aspects of sobriety and abstinence. Women 
also reported that "support site X" gave them a platform to celebrate abstinence and help others through sharing their own stories, again echoing other findings from [19].

Compared to "traditional" support, these women found "support site X" easier to access and better suited to individual needs. They felt traditional services were more focussed on the warnings/consequences of drinking rather than the positive aspects of abstinence "support site X" emphasises.

These are novel, if tentative, findings given that no studies were found that compared attitudes and experiences of social media support websites with traditional alcohol services. Despite evidence that early brief advice by GPs and other primary health professionals can be effective in reducing alcohol consumption [34], these mothers found GPs unhelpful or unrealistic in terms of suggestions, and avoided GPs for fear of (or prior experience of) repercussions relating to child protection, fears evidenced in previous literature [16]. Women who had some experience of AA felt it depressing, unhelpful, inconvenient or overly religious, in keeping with other findings [14].

These mothers found "support site X" to be an important supportive network, they felt part of a community and could get immediate personal advice from like-minded and experienced others. This reflects the concept of "shadow help" [9], whereby other people act as role models, provide useful information/advice and suggest self-help materials in supporting others. These women also identify the role "support site X" plays in maintaining vigilance against regressing to unhealthy drinking habits. Talking or reading about others who have relapsed after substantial periods of abstinence reinforces the need to remain guarded against problem drinking re-emerging as an issue in their lives.

\subsection{Factors Important in Sustaining Abstinence}

Positive parenting identity is an important aspect of sustaining abstinence for these women, primarily being a good mother and role model and seeing their children reaping the rewards of their abstinence. Similarly, finding alternatives to alcohol and keeping busy through a range of activities such as exercise and alcohol free entertainment were important. Sustaining abstinence brought rewards, these women emphasised their satisfaction, freedom and gratitude with alcohol free lives, concurring with previous research [35].

Although many mothers cited physical health rewards, mental health related rewards had equal, if not more, emphasis. These included increased positivity, self-esteem and confidence, again reflecting previous research.

Support from abstinent others was crucial in sustaining abstinence, reflecting findings elsewhere [36]. These mothers also distanced themselves from drinking environments and friendships based around alcohol, replicating previous findings [37]. Seeking out and befriending abstinent others may mitigate against potential factors of inferiority and threats to esteem brought about by experiencing issues related to alcohol problems. "Support site X" is aimed at women and given 
these mothers' negative experiences of traditional services offers support to the suggestion that gender specific support networks may further support successful abstinence [38].

\section{Implications for Practice}

Professional, educated mothers are underrepresented in alcohol research, yet represent a "hidden" group that health professionals should acknowledge. This is emphasised by emerging evidence that frequent heavy drinking causes more significant health consequences compared to episodic binge drinking [39]. The women in this sample did not resonate or engage with traditional services, preferring to engage with social media for support. This offers an opportunity for lead policy makers and service providers to consider the efficacy of social media in helping this population to address alcohol issues. Health Professionals should be mindful of negative media discourse regarding women and problem drinking, and mothers' fears of repercussions, particularly in relation to their children, in seeking help through traditional routes.

The cultural shift to home drinking and its normalisation contributes to high levels of unregulated drinking [8]. This sample were indicative of this habitual "home drinking" culture and did not regard themselves as stereotypical problem drinkers given they were drinking "nice" wine at home, were successful and meeting their commitments. Accordingly, Health Professionals should consider raising awareness amongst this population who may not resonate with negatively focussed categories such as dependent, hazardous or harmful drinking.

Health consequences did not exclusively enact change behaviour in this sample. These women cited positive benefits of alcohol free living and "role models" that they could easily identify with as inspiring the recognition of their alcohol issue and decision to address it. The rewards of alcohol free living were paramount in sustaining abstinence, leading to increased self-esteem and self-efficacy. Findings such as these aid understanding of the process of recovery and can be used to inform policy makers, programme developers and service providers in developing new strategies to enact behaviour change in such a hidden, hard to reach group. Disseminating information about the benefits of alcohol free living may be more effective than labouring the health consequences of drinking.

\section{Future Research}

Future research may look to recruit "pure" self-changers who turn solely to social media for support with alcohol. More focus upon the role of social media in alcohol recovery would enhance understanding regarding the processes involved. Further research that recruits female "experts by experience" differing in socio-demographic and socioeconomic status whilst exploring factors important in sustaining abstinence would also add substantively to the current knowledge base. 


\section{Conclusion}

Excessive home drinking is an issue for many UK mothers. Despite this, professional mothers may not resonate with stereotypical concepts of problem drinking, and be less likely to engage with traditional services that are seen as potentially punitive, stigmatising and inappropriate to their needs. Instead, many opt to engage with social media websites that provide inspiring, safe, pro alcohol free living messages and supportive communities. Messages emphasising negative health consequences alone are unlikely to enact behaviour change. Raising awareness of the benefits, rewards and helpful strategies in alcohol free living and doing so through real life stories and "role models" can augment positive outcomes in addressing alcohol misuse.

\section{References}

[1] ONS (2013) An Overview of 40 Years of Data (The 2011 General Lifestyle Survey). http://webarchive.nationalarchives.gov.uk/20160107023641/http://www.ons.gov.uk/ ons/publications/re-reference-tables.html?edition=tcm\%3A77-289713

[2] Office for National Statistics (2013) Chapter 2-Drinking (General Lifestyle Survey Overview-A Report on the 2011 General Lifestyle Survey). http://www.ons.gov.uk

[3] Lyons, A., McNeill, A. and Britton, J. (2014) Alcohol Imagery on Popularly Viewed tElevision in the UK. Journal of Public Health, 36, 426-434. https://doi.org/10.1093/pubmed/fdt074

[4] Emslie, C., Hunt, K. and Lyons, A. (2012) Older and wiser? Men's and women's Accounts of Drinking in Early Mid-Life. Sociology of Health \& Illness, 34, 481-496. https://doi.org/10.1111/j.1467-9566.2011.01424.x

[5] Salter, M. and Breckenridge, J. (2014) Women, Trauma and Substance Abuse: Understanding the Experiences of Female Survivors of Childhood Abuse in Alcohol and Drug Treatment. International Journal of Social Welfare, 23, 165-173. https://doi.org/10.1111/ijsw.12045

[6] Boden, J.M., Fergusson, D.M. and John Horwood, L. (2014) Associations between Exposure to Stressful Life Events and Alcohol Use Disorder in a Longitudinal Birth Cohort Studied to Age 30. Drug and Alcohol Dependence, 142, 154-160. https://doi.org/10.1016/j.drugalcdep.2014.06.010

[7] Kessler, R.C., Crum, R.M., Warner, L.A., et al. (1997) Lifetime Co-Occurence of DSM-III-R Alcohol Abuse and Dependence with Other Psychiatric Disorders in the National Comorbidity Survey". Archives of General Psychiatry, 54, 313-321. https://doi.org/10.1001/archpsyc.1997.01830160031005

[8] Ling, J., Smith, K.E., Wilson, G.B., Brieley-Jones, L., Crosland, A., Kaner, E.F.S. and Haighton, C.A. (2012) The "other" in Patterns of Drinking: A Qualitative Study of Attitudes towards Alcohol Use among Professional, Managerial and Clerical Workers". BMC Public Health, 12, 892-899.

http://www.biomedcentral.com/1471-2458/12/892

[9] Witbrodt, J., Borkman, T.J., Stunz, A. and Subbaraman, M.S. (2014) Mixed Methods Study of Help Seekers and Self-Changers Responding to an Online Recovery Survey. Alcohol and Alcoholism, 50, 82-88. https://doi.org/10.1093/alcalc/agu077

[10] Best, D., Gow, J., Taylor, A., Know, A. and White, W. (2011) Recovery from Heroin or Alcohol Dependence: A Qualitative Account of the Recovery Experience in Glasgow. Journal of Drug Issues, 41, 359-378. https://doi.org/10.1177/002204261104100303 
[11] Carlson, B., Smith, C., Matto, H. and Eversman, M. (2008) Reunification with Children in the Context of Maternal Recovery from Drug Abuse. Families in Society: The Journal of Contemporary Social Services, 89, 253-263. https://doi.org/10.1606/1044-3894.3741

[12] Spillane, N.S., Greenfield, B., Venner, K. and Kahler, C.W. (2015) Alcohol Use among Reserve-Dwelling Adult First Nation Members: Use, Problems, and Intention to Change Drinking Behaviour. Addictive Behaviours, 41, 232-237. https://doi.org/10.1016/j.addbeh.2014.10.015

[13] Oleski, J., Mota, N., Cox, B.J. and Sreen, J. (2010) Perceived Need for Care, Help Seeking, and Barriers to Care for Alcohol Use Disorders in a National Sample. Psychiatric Services, 61, 1223-1231. https://doi.org/10.1176/ps.2010.61.12.1223

[14] Brown, S., Tracy, E.M., Jun, M., et al. (2015) Personal Network Recovery Enablers and Relapse Risks for Women with Substance Dependence. Qualitative Health Research, 25, 371-385. https://doi.org/10.1177/1049732314551055

[15] Simon, J.M. (2014) Disciplining Drunken Mothers: Media Representations of Women's Use of Alcohol. The Communication Review, 17, 45-64. https://doi.org/10.1080/10714421.2014.872499

[16] LaFave, L., Desported, L. and McBride, C. (2009) Treatment Outcomes and Perceived Benefits: A Qualitative and Quantitative Assessment of a Women's Substance Abuse Treatment Program. Women \& Therapy, 32, 51-68. https://doi.org/10.1080/02703140802384743

[17] Szabo, J. and Gerevich, J. (2013) Alcohol Dependency, Recovery, and Social Words. Journal of Applied Social Psychology, 43, 806-810.

[18] Dawson, D.A., Grant, B.F., Stinson, F.S., et al. (2005) Recovery from DSM-IV Alcohol Dependence: United States, 2001-2002. Addiction, 100, 281-292. https://doi.org/10.1111/j.1360-0443.2004.00964.x

[19] Mudry, T.E and Strong, T. (2012) Doing Recovery Online. Qualitative Health Research, 23, 313-325. https://doi.org/10.1177/1049732312468296

[20] Finfgeld-Connett, D. and Madsen, R. (2008) Web Based Treatment of Alcohol Problems among Rural Women: Results of a Randomized Pilot Investigation. Journal of Psychosocial Nursing and Mental Health Services, 46, 46-53. https://doi.org/10.3928/02793695-20080901-05

[21] Office for National Statistics (ONS) (2015) Internet Access-Households and Individuals 2015. Statistical Bulletin. http://www.ons.gov.uk/ons/dcp171778_412758.pdf

[22] Cooper, G. (2004) Exploring and Understanding Online Assistance for Problem Gamblers: The Pathways Disclosure Model. E-Community International Journal of Mental Health \& Addiction, 1, 32-38.

http://www.abgam-blinginstitute.ualberta.ca/LibraryResources/JournalTitles/eCOM MUNITY.aspx

[23] Smith, C.P. (2000) Content Analysis and Narrative Analysis. In: Reis, H.T. and Judd, C.M., Eds., Handbook of Research Methods in Social and Personality Psychology, Cambridge University Press, New York.

[24] Lyons, N. and LaBoskey, V.L. (2002) Narrative Inquiry in Practice: Advancing the Knowledge of Teaching. Teachers College Press, New York.

[25] Braun, V. and Clarke, V. (2006) Using Thematic Analysis in Psychology. Qualitative Research in Psychology, 3, 77-101. https://doi.org/10.1191/1478088706qp063oa 
[26] Pitstrang, N. and Barker, C. (2012) Varieties of Qualitative Research: A Pragmatic Approach to Selecting Methods. In: Cooper, H., Ed., APA Handbook of Research Methods in Psychology, Vol. 2 Research Designs, American Psychological Association, Washington DC.

[27] Elliott, R., Fischer, C.T. and Rennie, D.L. (1999) Evolving Guidelines for Publication of Qualitative Research Studies in Psychology and Related Fields. British Journal of Clinical Psychology, 38, 215-229. https://doi.org/10.1348/014466599162782

[28] Watts, R., Linke, S., Murray, E. and Barker, C. (2015) Calling the Shots: Young Professional Women's Relationship with Alcohol. Feminism \& Psychology, 25, 219-234. https://doi.org/10.1177/0959353515571670

[29] Weissman, M.M., Bland, R.C., Canino, G.J., et al. (1996) Cross-National Epidemiology of Major Depression and Bipolar Disorder. JAMA, 276, 293-299.

https://doi.org/10.1001/jama.1996.03540040037030

[30] Brierley-Jones, L., Ling, J., McCabe, K.E., et al. (2014) Habitus of Home and Traditional Drinking: A Qualitative Analysis of Reported Middle-Class Alcohol Use. Sociology of Health \& Illness, 36, 1054-1076. https://doi.org/10.1111/1467-9566.12145

[31] Kuntsche, E., Knibbe, R. and Gmel, G. (2010) A Step Beyond-The Relevance of Depressed Mood and Mastery in the Interplay between the Number of Social Roles and Alcohol Use. Addictive Behaviors, 35, 1013-1020.

[32] Klingemann, H.K.H. (1991) The Motivation for Change from Problem Alcohol and Heroin Use. British Journal of Addiction, 86, 727-744.

https://doi.org/10.1111/j.1360-0443.1991.tb03099.x

[33] Thom, B. (1986) Sex Differences in Help-Seeking for Alcohol Problems 1. The Barriers to Help Seeking. British Journal of Addiction, 81, 777-788. https://doi.org/10.1111/j.1360-0443.1986.tb00405.x

[34] Moyer, A. and Finney, J.W. (2015) Brief Interventions for Alcohol Misuse. CMAJ, 187, 502-506. https://doi.org/10.1503/cmaj.140254

[35] Laudet, A.B., Becker, J.B. and White, W.L. (2009) Don't Wanna Go through That Madness No More: Quality of Life Satisfaction as Predictor of Sustained Remission from Illicit Drug Misuse. Substance Use and Misuse, 44, 227-252. https://doi.org/10.1080/10826080802714462

[36] Weisner, C., Delucchi, K., Matzger, H. and Schmidt, L. (2003) The Role of Community Services and Informal Support on Five-Year Drinking Trajectories of Alcohol Dependent and Problem Drinkers. Journal of Studies on Alcohol, 64, 862-873. https://doi.org/10.15288/jsa.2003.64.862

[37] Warren, J.I., Stein, J.A. and Grella, C.E. (2007) Role of Social Support and Self Efficacy in Treatment Outcomes among Clients with Co-Occurring Disorders. Drug and Alcohol Dependence, 89, 267-274.

[38] Hunter, B.A., Jason, L.A. and Keys, C.B. (2013) Factors of Empowerment for Women in Recovery from Substance Use. American Journal of Community Psychology, 51, 91-102. https://doi.org/10.1007/s10464-012-9499-5

[39] Szmigin, I., Griffin, C., Mistral, W., Bengry-Howell, A., Weale, L. and Hackley, C. (2008) Re-Framing Binge Drinking as Calculated Hedonism: Empirical Evidence from the UK. International Journal of Drug Policy, 19, 359-366.

https://doi.org/10.1016/j.drugpo.2007.08.009 